Pengembangan Rekayasa dan Teknologi, Vol 15, No. 1, Juni 2019, pp 43-47

p-ISSN: $1410-9840$ \& e-ISSN: 2580-8850

http://journals.usm.ac.id/index.php/jprt/index

\title{
PENGGUNAAN METODE K-MEANS PADA ANALISA DAN KLASIFIKASI CAPRES 2019 DI TWITTER
}

\author{
Ahmad Rifa'i ${ }^{1}$, Galet Guntoro Setiaji ${ }^{2}$, Vensy Vydia ${ }^{3}$ \\ ${ }^{1,2,3}$ Fakultas Teknologi Informasi dan Komunikasi, Universitas Semarang \\ ${ }^{1}$ rifai@usm.ac.id. ${ }^{2}$ gallet@usm.ac.id, ${ }^{3}$ vensy@usm.ac.id
}

\begin{abstract}
ABSTRAK
Media sosial merupakan wadah untuk mencurahkan kata-kata melalui tulisan pada dunia maya (online), sehingga pada nantinya akan dapat dilihat oleh banyak orang baik yang dikenal maupun tidak dikenal. Twitter merupakan jejaring sosial atau media sosial yang memiliki teks terbatas, yaitu memiliki Panjang teks sebanyak 280 karakter. Metode crawling merupakan metode yag digunakan untuk pengambilan data dari media sosial yang dapat digunakan sebagai developer application.

Crawling data pada media sosial twitter ini menggunakan aplikasi spyder python 3.7 yang berada didalam aplikasi anaconda. Dengan aplikasi tersebut akan di dapatkan data-data berkenaan dengan capres 2019. data-data tersebut akan diolah menggunakan metode K-Means. Setelah dilakukan pengolahan data menggunakan K-Means di dapatkan untuk cluster 1 (Jokowi) muncul sebanyak 3 kali sedangkan untuk cluster 2 (Prabowo) muncul sebanyak 1 kali.
\end{abstract}

\section{ABSTRACT}

Social media is a place to devote words through writing to the online world, so that in the future it can be seen by many people, both known and unknown. Twitter is a social network or social media that has limited text, which has a text length of 280 characters. The crawling method is a method used to extract data from social media that can be used as an application developer.

Data crawling on social media Twitter uses the Spyder Python 3.7 application that is in the Anaconda application. With the application, the data will be obtained regarding the 2019 presidential candidate. The data will be processed using the K-Means method. After processing data using K-Means, it was obtained for cluster 1 (Jokowi) to appear 3 times while cluster 2 (Prabowo) appeared 1 time..

Keyword: Social Media, Twitter, Crawling Data, K-Means

\section{Pendahuluan}

Media sosial dijaman sekarang merupakan wadah untuk tempat mencurahkan kata-kata lewat tulisan, dimana tulisan itu nantinya bisa dilihat oleh semua orang yang dikenal atau tidak. Dari sini media sosial merupakan alat yang bisa mempengaruhi seseorang bahkan sekelompok orang. Media sosial yang kita kenal diantaranya facebook, instagram dan twitter yang sebagian besar media sosial ini digunakan mulai pertemanan hingga perang argument.

Dimana salah satunya sebagian peneliti juga menggunakan media sosial sebagai pengumpul data, disini paling sering digunakan yaitu media sosial twitter. Kenapa menggunakan media sosial twitter, karena media sosial ini memiliki apps yang bisa digunakan sebagai developer application. Dimana data-data yang ingin di cari dapat diambil dengan metode crawling.

Disini kita mengambil atau mengcrawling dengan focus data tentang calon presiden Indonesia tahun 2019. Dimana nanti data crawling digunakan sebagai data set, yang diolah dengan sebuah metode data mining yaitu k-means. Diharapkan dari sebuah data itu nantinya akan memberikan sebuah informasi.

\section{Data Mining}

Data mining didefinisikan sebagai proses mengekstrak atau menambang pengetahuan yang dibutuhkan dari sejumlah data besar (Han dan Kamber, 2006 : 5). Pada prosesnya data mining akan mengekstrak informasi yang berharga dengan cara menganalisis adanya pola-pola ataupun hubungan keterkaitan tertentu dari data-data yang berukuran besar. Data mining berkaitan dengan bidang ilmu- 
ilmu lain, seperti Database System, Data Warehousing, Statistic, Machine Learning, Information Retrieval, dan Komputasi Tingkat Tinggi. Selain itu data mining didukung oleh ilmu lain seperti Neural Network, Pengenalan Pola, Spatial Data Analysis, Image Database, Signal Processing.

Pengetahuan yang dihasilkan dari proses data mining harus baru, mudah dimengerti, dan bermanfaat. Dalam data mining, data disimpan secara elektronik dan diproses secara otomatis oleh komputer menggunakan teknik dan perhitungan tertentu (Pramadhani dan Setiadi, 2014).

Menurut Maclennan, Tang, \& Crivat (2009, p6). Berikut adalah fungsi data mining secara umum :

1. Classification

Classification adalah proses untuk mencari model atau fungsi yang menggambarkan dan membedakan kelas-kelas atau konsep data. Fungsi dari Classification adalah untuk mengklasifikasikan suatu target class ke dalam kategori yang dipilih.

2. Clustering

Fungsi dari clustering adalah untuk mencari pengelompokkan atribut ke dalam segmentasi-segmentasi berdasarkan similaritas.

3. Association

Fungsi dari association adalah untuk mencari keterkaitan antara atribut atau item set, berdasarkan jumlah item yang muncul dan rule association yang ada

4. Regression

Fungsi dari regression hampir sama dengan klasifikasi. Fungsi dari regression adalah bertujuan untuk mencari prediksi dari suatu pola yang ada

5. $\quad$ Forecasting

Fungsi dari forecasting adalah untuk peramalan waktu yang akan datang berdasarkan trend yang telah terjadi di waktu sebelumnya

6. Sequence Analysis
Fungsi dari sequence analysis adalah untuk mencari pola urutan dari rangkaian kejadian

\section{Deviation Analysis}

Fungsi dari deviation analysis adalah untuk mencari kejadian langka yang sangat berbeda dari keadaan normal (kejadian abnormal).

\subsection{Algoritma K-Means}

K-Means merupakan salah satu metode pengelompokan data nonhierarki (sekatan) yang berusaha mempartisi data yang ada ke dalam bentuk dua atau lebih kelompok (Krisna, 2016). Metode ini mempartisi data kedalam kelompok yang lain. Adapun tujuan pengelompokan data ini adalah meminimalkan variasi didalam suatu kelompok dam memaksimalkan variasi antar kelompok. Dengan mengunakan teknik klustering dalam K-means, maka tahapan algoritma K-means adalah sebagai berikut :

a. Menentukan koordinat titik tengah setiap cluster

b. Menentukan jarak setiap onjek terhadap kordinat titik tengah

c. Mengelompokan objek-objek tersebut berdasarkan pada jarak minimumnya

d. Tentukan pusat cluster baru

e. Apakah ada selisih antar cluster lama dengan baru?jika masih ada kembali ke langkah a hingga

$\mathrm{d}$, jika tidak selesai.

Di dalam menentukan titik centroid kita menggunakan perhitungan jarak Euclidian distance, dengan rumus sebagai berikut :

$$
\begin{aligned}
& d_{i j}=\sqrt{\left[\left(x_{i}-x_{j}\right)^{2}+\left(y_{i}-y_{j}\right)^{2}\right]} \\
& x_{i}=\text { koordinat } \mathrm{x} \text { untuk fasilitas } \mathrm{i} \\
& y_{i}=\text { koordinat } \mathrm{y} \text { untuk fasilitas } \mathrm{i} \\
& d_{i j}=\text { jarak antar fasilitas I dan } \mathrm{j}
\end{aligned}
$$

\subsection{Proses Crawling Data Twitter}

Dalam melakukan crawling data pada sosial media twitter ada beberapa proses yang terjadi diantaranya:

a. Konfigurasi API twitter

Proses yang dilakukan sebelum melakukan crawling data yaitu melakukan twitter authentication dengan mengisikan 
consumer_key, consumer_secret, access_token, access_secret.

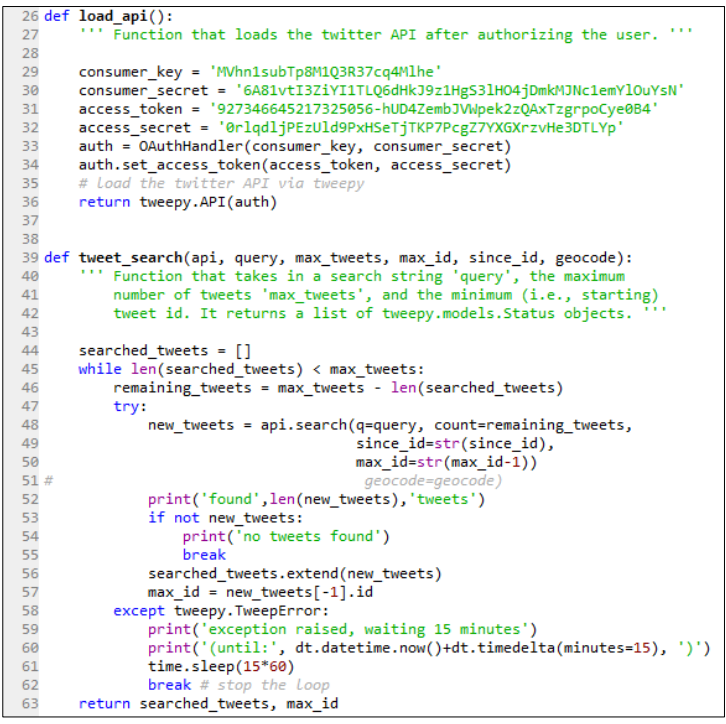

Gambar 1. Konfigurasi API Twitter

b. Konfigurasi Crawling Data

Masukkan ketentuan-ketentuan data yang akan diambil dari sosial media twitter yaitu meliputi hastag, maksimal tweet dan rentang waktu pengambilan data.

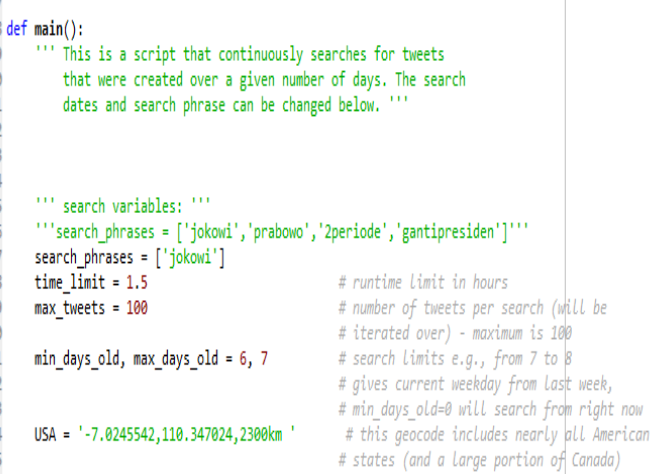

Gambar 2. Konfigurasi Crawling Data

\subsection{Proses Olah Data dengan K-Mean}

Data yang sudah di normalisasi sekitar 1000 data yang berisi tentang hastag jokowi dan hastag Prabowo. Dengan terkumpulnya data maka langkah selanjutnya adalah mengolah dengan algoritma KMeans, langkah-langkahnya sebagai berikut :

1. Menentukan Awalan Cluster Secara Random
Disini kita akan melakukan penelitian sebanyak 4 kali, dan menentukan $\mathrm{K}$ awal juga sebanyak 4 data $\mathrm{K}$.

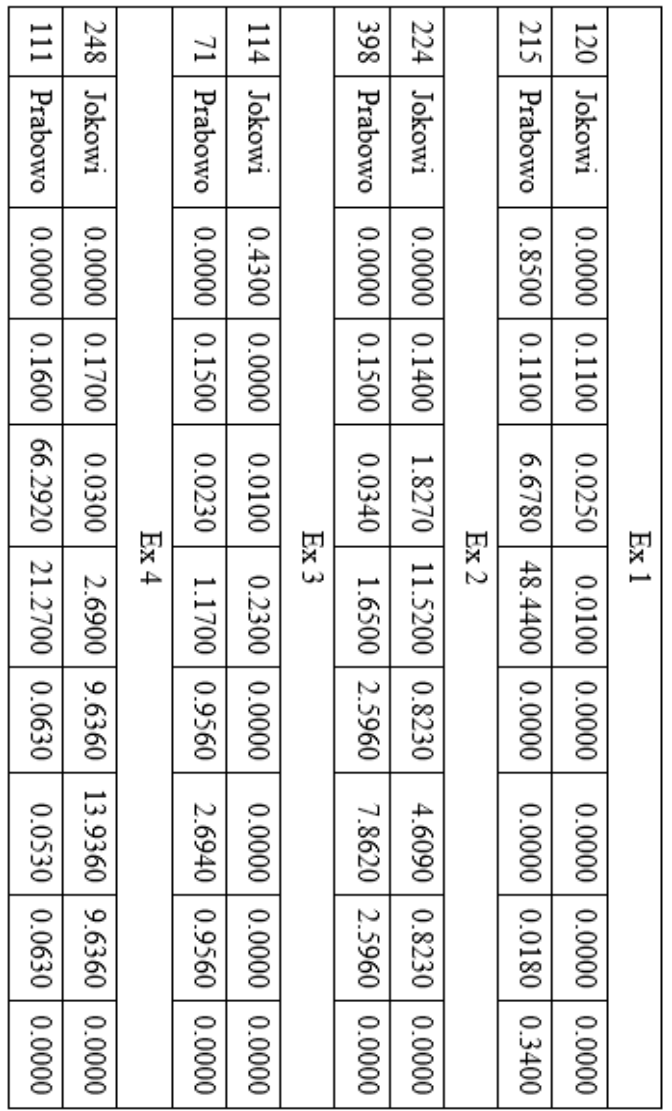

Gambar 3. Menentukan Awalan Cluster Secara Random

2. Perhitungan Jarak Pusat Cluster

Pengukuran jarak antara data dengan pusat cluster menggunakan Euclidian distance. Dari perhitungan tersebut didapatkan nilai dari Cluster 1 dan nilai dari Cluster 2. Nilai terendah akan diambil sebgai Cluster yang dipilih.

\begin{tabular}{|c|c|c|c|}
\hline $\mathrm{C} 1$ & $\mathrm{C} 2$ & Min & $\mathrm{C}$ \\
\hline 4.7914 & 47.8780 & 4.7914 & $\mathrm{C} 1$ \\
\hline 69.5223 & 21.2119 & 21.2119 & $\mathrm{C} 2$ \\
\hline 1.0077 & 48.0451 & 1.0077 & $\mathrm{C} 1$ \\
\hline 9.5421 & 39.4339 & 9.5421 & $\mathrm{C} 1$ \\
\hline 11.4388 & 46.1419 & 11.4388 & $\mathrm{C} 1$ \\
\hline 0.9772 & 48.0741 & 0.9772 & $\mathrm{C} 1$ \\
\hline 1.6959 & 47.2003 & 1.6959 & $\mathrm{C} 1$ \\
\hline 2.0223 & 46.8740 & 2.0223 & $\mathrm{C} 1$ \\
\hline
\end{tabular}


p-ISSN: $1410-9840 \&$ e-ISSN: $2580-8850$

\begin{tabular}{|c|c|c|c|}
\hline $\mathrm{C} 1$ & $\mathrm{C} 2$ & Min & $\mathrm{C}$ \\
\hline 9.0814 & 39.8424 & 9.0814 & $\mathrm{C} 1$ \\
\hline 11.9927 & 46.0510 & 11.9927 & $\mathrm{C} 1$ \\
\hline 0.9563 & 47.9505 & 0.9563 & $\mathrm{C} 1$ \\
\hline 0.8773 & 48.0283 & 0.8773 & $\mathrm{C} 1$ \\
\hline 9.3527 & 39.5524 & 9.3527 & $\mathrm{C} 1$ \\
\hline 1.1202 & 47.7815 & 1.1202 & $\mathrm{C} 1$ \\
\hline 14.4568 & 34.5645 & 14.4568 & $\mathrm{C} 1$ \\
\hline 4.9058 & 44.0202 & 4.9058 & $\mathrm{C} 1$ \\
\hline
\end{tabular}

Tabel 1. Perhitungan Jarak Pusat Cluster

3. Pengelompokan Data dan Menentukan Pusat Cluster Terbaru

Setelah dilakukan perhitungan, langkah selanjutnya adalah melakukan pengelompokan data dan menetukan pusat cluster terbaru.

\begin{tabular}{|c|c|}
\hline Jokowi & Prabowo \\
\hline 0.161986 & 0 \\
\hline 0.119178 & 0.093333 \\
\hline 2.054158 & 1283.388 \\
\hline 6.365466 & 0.236667 \\
\hline 0.711456 & 0.012 \\
\hline 1.532297 & 0.044 \\
\hline 0.712572 & 0.018 \\
\hline 0.020271 & 0.22 \\
\hline
\end{tabular}

Tabel 2. Pengelompokan Data dan Menentukan Pusat Cluster Terbaru

4. Ulangi langkah ke 2 dan 3 hinga pusat cluster baru tidak berubah

Hasil objek Interasi ke 1

\begin{tabular}{|l|r|}
\hline Fungsi Objektif Awal & 1000.00 \\
\hline Fungsi Objektif J & 734.49 \\
\hline Fungsi Objektif & $\mathbf{2 6 5 . 5 1}$ \\
\hline
\end{tabular}

Tabel 3. Hasil Objek Iterasi ke 1

Hasil objek Interasi ke 13 didapatkan fungsi objektif

\begin{tabular}{|l|r|}
\hline Fungsi Objektif Awal & 680.81 \\
\hline Fungsi Objektif J & 680.81 \\
\hline Fungsi Objektif & $\mathbf{0 . 0 0}$ \\
\hline
\end{tabular}

Tabel 4. Hasil objek Interasi ke 13 didapatkan fungsi objektif
5. Dari 4 tahapan diatas dan 4 kali penelitian dihasilkan data sebagai sebagai berikut

\begin{tabular}{|c|c|c|}
\hline Penelitian & Interasi & Cluster \\
\hline 1 & $5 \mathrm{x}$ & $\mathrm{C} 1$ \\
\hline 2 & $6 \mathrm{x}$ & $\mathrm{C} 2$ \\
\hline 3 & $7 \mathrm{x}$ & $\mathrm{C} 1$ \\
\hline 4 & $4 \mathrm{x}$ & $\mathrm{C} 1$ \\
\hline
\end{tabular}

Tabel 5. Hasil 4 Kali Tahapan

6. Cara mengitung DBI

- Menghitung Sum of square within Cluster (SSW)

$$
S S W_{i}=\frac{1}{m_{i}} \sum_{j=1}^{m_{i}} d\left(x_{j}, c_{i}\right)
$$

\begin{tabular}{|l|l|}
\hline SSW 1 & 8.956667 \\
\hline SSW 2 & 384.0227 \\
\hline
\end{tabular}

- Menghitung Sum of square between cluster (SSB)

$$
S S S B_{i, j}=d\left(c_{i}, c_{j}\right)
$$

\begin{tabular}{|c|c|c|c|}
\hline \multicolumn{2}{|c|}{ SSB } & \multicolumn{2}{c|}{ Data ke $\boldsymbol{i}$} \\
\cline { 3 - 4 } \multicolumn{2}{|c|}{} & 1 & 2 \\
\hline \multirow{2}{*}{$\begin{array}{c}\text { Data } \\
\text { ke } \boldsymbol{i}\end{array}$} & 1 & 0.0000 & 1281.3494 \\
\cline { 2 - 4 } & 2 & 1281.3494 & 0.0000 \\
\hline
\end{tabular}

- Mendefinisikan ukuran rasio seberapa baik nilai atara cluster $\left(R_{i, j}\right)$

$$
R_{i, j}=\frac{S S W_{i}+S S W_{j}}{S S B_{i, j}}
$$

- $\quad$ Menghitung Davis-Bouldin Index (DBI)

$$
D B I=\frac{1}{K} \sum_{i=1}^{K} \max _{i \neq j}\left(R_{i, j}\right)
$$

\begin{tabular}{|c|c|c|c|c|c|}
\hline \multicolumn{2}{|c|}{ R } & \multicolumn{2}{c|}{ Data ke } & \multicolumn{2}{c}{} \\
\cline { 3 - 5 } \multicolumn{2}{|c|}{} & 1 & 2 & Rmax & DBI \\
\hline \multirow{2}{*}{$\begin{array}{c}\text { Data } \\
\text { ke } \boldsymbol{i}\end{array}$} & 1 & 0 & 0.78 & 0.78 & \multirow{2}{*}{$\mathbf{0 . 5 2}$} \\
\cline { 2 - 5 } & 2 & 0.78 & 0 & 0.78 & \\
\hline
\end{tabular}


Sehingga

a. Hasil perhitungan K-Means dipengaruhi saat penentuan nilai awal $\mathrm{k}$

b. Dari 4 data awal dan 4 kali penelitian KMeans dapatkan cluster pertama yang lebih besar nilainya.

c. Dari 4 tahapan tersebut di dapatkan kemunculan Cluster 1 sebanyak 3 kali dan kemunculan Cluster 2 sebanyak 1 kali

d. Validitas Mengunakan DBI dari ke empat data, didapatkan validitas sebesar $\mathbf{0 . 5 2}$

\section{Kesimpulan}

Crawling data pada media sosial twitter ini menggunakan aplikasi spyder python 3.7 yang berada didalam aplikasi anaconda. Dengan aplikasi tersebut akan di dapatkan data-data berkenaan dengan capres 2019. data-data tersebut akan diolah menggunakan metode $K$-Means. Setelah dilakukan pengolahan data menggunakan K-Means di dapatkan untuk cluster 1 (Jokowi) muncul sebanyak 3 kali sedangkan untuk cluster 2 (Prabowo) muncul sebanyak 1 kali. Dari ke empat data, didapatkan validitas menggunakan DBI sebesar $\mathbf{0 . 5 2}$

\section{Daftar Pustaka}

Astuti, Fajar Hermawati (2013). Data Mining. Andi Publisher

Han, Jiawei dan Kamber, Micheline. (2007), Data Mining : Concept and Techniques Second Edition, Morgan Kaufmann Publishers.

J. MacLennan, Z. Tang and B. Crivat. (2009). Scalable Varied Density Clustering Algorithm for Large Datasets. Journal of Software Engineering and Applications, Vol.3 No.6

Kusrini dan EmhaTaufiq Lutfi (2009). Algoritma Data Mining. Andi Publisher

Prasetyo, Eko (2013). Data Mining (Konsep dan Aplikasi Menggunakan Matlab). Andi Publisher

Pramadhani, A., Embun \& Setiadi, T. (2014). Penerapan Data Mining untuk Klasifikasi Prediksi Penyakit Ispa dengan Algoritma Decision Tree (ID3), Jurnal Sarjana Teknik Informatika Volume 2 Nomor 1 e-ISSN: 2338-5197

Prasetyo, Eko (2014). Data Mining Mengolah Data Menjadi Informasi Menggunakan Matlab. Andi Publisher

Wardhani, A., Krisna. (2016). Implementasi Algoritma K-Means Untuk Pengelompokkan Penyakit Pasien Pada Puskesmas Kajen Pekalongan, Jurnal Transformatika, Volume 14, Nomor 1. 